\title{
Diabetes through a 3D lens: organoid models
}

\author{
Anastasia Tsakmaki $^{1}$ (D) Patricia Fonseca Pedro ${ }^{1}$ (I) $\cdot$ Gavin A. Bewick ${ }^{1}$
}

Received: 28 November 2019 / Accepted: 6 February 2020/Published online: 27 March 2020

(C) The Author(s) 2020

\begin{abstract}
Diabetes is one of the most challenging health concerns facing society. Available drugs treat the symptoms but there is no cure. This presents an urgent need to better understand human diabetes in order to develop improved treatments or target remission. New disease models need to be developed that more accurately describe the pathology of diabetes. Organoid technology provides an opportunity to fill this knowledge gap. Organoids are 3D structures, established from pluripotent stem cells or adult stem/progenitor cells, that recapitulate key aspects of the in vivo tissues they mimic. In this review we briefly introduce organoids and their benefits; we focus on organoids generated from tissues important for glucose homeostasis and tissues associated with diabetic complications. We hope this review serves as a touchstone to demonstrate how organoid technology extends the research toolbox and can deliver a step change of discovery in the field of diabetes.
\end{abstract}

Keywords 3D culture $\cdot$ Beta cells $\cdot$ Diabetes $\cdot$ Diabetic complications $\cdot$ Disease modelling $\cdot$ Glucose homeostasis $\cdot$ Obesity Organoids $\cdot$ Review $\cdot$ Stem cells

$\begin{array}{ll}\text { Abbreviations } \\ \text { ASC } & \text { Adult tissue-resident stem cell } \\ \text { EEC } & \text { Enteroendocrine cell } \\ \text { HIO } & \text { Human intestinal organoid } \\ \text { iPSC } & \text { Induced pluripotent stem cell } \\ \text { MSC } & \text { Mesenchymal stem cell } \\ \text { NAFLD } & \text { Non-alcoholic fatty liver disease } \\ \text { NASH } & \text { Non-alcoholic steatohepatitis } \\ \text { PSC } & \text { Pluripotent stem cell }\end{array}$

\section{What are organoids?}

The past decade has born witness to the meteoric rise of organoid technology, a long-term heterogenous stem cell-

Electronic supplementary material The online version of this article (https://doi.org/10.1007/s00125-020-05126-3) contains a slideset of the figures for download, which is available to authorised users.

Gavin A. Bewick

gavin.bewick@kcl.ac.uk

1 Faculty of Life Sciences and Medicine, School of Life Course Sciences, Department of Diabetes, Diabetes Research Group, Hodgkin Building, King's College London, Guy's Campus, London SE1 1UL, UK based culture technique, chosen as Nature method of the year 2017 [1]. Organoids have transformative potential; they will help us to better model human diseases, leading to the development of novel treatments, the revolutionising of personalised medicine and the acceleration of regenerative medicine. But what exactly are organoids? The definition of an organoid has been nebulous, owing to its use in describing the many different types of 3D culture systems developed in the last 50 years [2]. Since the development of intestinal stem cell-derived organoid cultures in 2009 (discussed in the Text box: 'Genesis of the modern organoid field'), the term now refers to a specific set of working criteria. The current definition requires an organoid to be established from pluripotent stem cells or adult stem/progenitor cells, to demonstrate a $3 \mathrm{D}$ structure resembling the in vivo organ landscape, exhibit an array of cell types found in vivo and demonstrate some aspects of the specialised functions of the tissues [3-5].

\section{A step change in disease modelling}

A staple tool of the medical research community is the modelling of cellular function and disease in vitro. In a dish, experimental variables can be accurately controlled, cells can easily be manipulated, and outputs measured by standard and highthroughput technologies. Cell lines and explant cultures have traditionally been used, but both have limitations. 2D-cultured 


\section{Genesis of the modern organoid field}

There were two major leaps that led to the development of modern organoid methods: first, the realisation that a greater understanding of the steps leading to organ development and the factors controlling them was needed; and second, identification of the minimal stem cell niche factors required to maintain self-renewal and direct morphogenesis was essential [7]. Using these as starting points, two groups developed intestinal organoids from different stem-cell sources: ASCs and PSCs.

In 2009, Sato and colleagues described the generation of single $\mathrm{Lgr}^{+}$stem cell-derived organoids and organoids established from purified mouse or human adult intestinal crypts [8, 9]. This discovery was facilitated by earlier studies identifying the extracellular matrix and key growth factors, such as EGF, Noggin and $\mathrm{R}$-spondin, as crucial components of the intestinal stem-cell niche [8]. In this in vitro niche, isolated crypts or single intestinal stem cells quickly form cystic structures composed of a central lumen lined by a layer of epithelial cells. They further develop into complex multicellular self-renewing structures, displaying the full range of expected cell types, organised with defined crypt- and villus-like regions closely resembling the in vivo architecture $[8,10,11]$. These cultures remained unchanged, with no evidence of chromosome rearrangement, even after several years of passaging [12].

In parallel, James Wells and colleagues pioneered the conversion of PSCs into intestinal organoids by directed differentiation, a stepwise approach that mimics embryonic intestinal development. This type of organoid is often termed 'human intestinal organoid' (HIO) [13-16]. Following differentiation, HIOs are also grown in a 3D matrix with the same growth factors as their ASC counterparts. Similarly, they closely resemble the intestinal architecture and cell composition in vivo. While ASC-derived organoids contain only epithelial cells, HIOs also contain mesenchymal-derived cells, including myofibroblasts and smooth muscle cells. However, PSC-derived organoids are generally considered developmentally more immature [17].

Both methods proved seminal and have given rise to the development of organoids from diverse and everincreasing tissue types, including tongue, lung, liver, kidney, pancreas, prostate, mammary, brain and inner ear.

cells may not act in vitro as they would in vivo, because they are not grown in conditions that adequately mimic the in vivo microenvironment. In addition, cell lines are transformed, making these cells far from 'normal', calling into question how representative of physiology they really are. In contrast, explant cultures are a more physiologically relevant model as they contain a heterogenous population of primary cells representative of the tissue of origin. However, these cultures cannot be maintained for long periods, which increases the need for multiple tissue donors, and they are generally difficult to genetically manipulate. Organoid cultures address many of these shortcomings as they are complex 3D, multicellular, self-renewing primary tissue structures that can be cultured over months to years without losing their faithful near physiological representation of the tissues they mimic [6]. These properties provide the research community with a step change in our ability to model diseases on the bench.

\section{What can organoids do for you?}

The power of organoids lies in their ability to be cultured from human patient-derived adult tissue-resident stem cells (ASCs) or pluripotent stem cells (PSCs), paving the way for personalised medicine and primary tissue disease modelling $[18,19]$. Although, as with any model, organoids are not without limitations (See Text box: 'Don't believe the hype: organoid limitations'). Currently organoids have been used to investigate gene function, cell development, tissue and cellular level physiology and model host-microbiome interactions. They are also useful for modelling infectious and genetic diseases, investigating primary tumour growth, and have applications in drug screening and regenerative medicine $[20,21]$. A further key driver of their utility, in addition to being a more physiologically relevant model, is their amenability to both standard and high-tech laboratory techniques and their genetic and molecular tractability. For example, organoids can easily be manipulated using viral and nonviral mediated delivery of CRISPR-Cas9 gene editing [22], they can be investigated using mass spectrometry [23], flow cytometry [24], multiple single cell 'omics' technologies [25] and naturally their 3D structure lends themselves to all manner of imaging technologies [26] (Fig. 1). This flexibility provides exciting opportunities for the generation of organoids from multiple organs and disease sources, coupled with their manipulation and phenotypic investigation.

\section{Mini-me: Modelling diabetes in a dish}

Organoid technology has the power to accelerate diabetes research, particularly cell replacement therapies. The 
Don't believe all the hype: organoids are not perfect. There are key considerations to be acknowledged when using this technology and important limitations that the field needs to overcome. Foremost is the lack of many of the essential components of the living organ they represent. For example, organoids do not have integrated nervous, vascular, or functional adaptive and innate immune systems. Generating more complex organoid models is a current focus of the field and many labs have refined co-culture techniques to enable the addition of immune cells [27, 28], a functioning nervous system [29] and microbial interactions (including pathogens [30] and intestinal microbiota [31]), or included endothelial or mesenchymal cells to increase maturity [32].

However, the maturity of organoid models remains the most challenging aspect of improving the technology. Orthotopic transplantation of PSC-derived organoids at various tissue sites produces organoids/tissue structures that more closely resemble the native tissue [32]. In the case of intestinal organoids, kidneycapsule transplantation induces organoids to develop into segments of gut 1-2 mm in length [33]. Similarly, human pancreatic organoids consisting of acinar/ductal-like progeny were generated from human PSCs and further matured following transplantation [34].

Other disadvantages are reflected in the inconsistencies in growth rate and differentiation time between cultures from different labs, which is, in part, driven by the variability in the reagents used for culturing organoids. The technology almost universally requires a 3D matrix. The two main products favoured by the field are Matrigel Matrix and Basement Membrane Extract (BME). They both exhibit batch-to-batch variation and being animal derived means that they cannot be used for clinical transplantations. This has led to the development of synthetic functionalised matrices, the physical properties of which can be controlled and be produced with improved consistency, and which could be developed for clinical use [35]. Equally, there are considerable issues with the media used to culture organoids. To reduce the costs of using recombinant growth factors, many labs grow their own conditioned media, particularly for Wnt-3A, Noggin and R-spondin. There is considerable intra- and inter-lab variation in the concentration of growth factor produced in different batches. In addition, the media used to culture organoids is not physiological. For example, intestinal organoids are routinely grown in high glucose concentrations, which is not reflective of the normal gut stemcell environment in a healthy individual.

The 3D multicellular composition of an organoid is a strength but also a weakness. For example, accessing the intact organoid lumen is not easy, making the study of host-microbiome interactions and nutritional research more difficult. To overcome this, organoids can be micro-injected [36], which is time consuming, or plated in 2D on a semi-permeable membrane, allowing access to both apical and basolateral surfaces [37, 38], or grown in suspension culture, which inverts their polarity, turning them inside-out [39].

One of the benefits of patient-derived organoids is that they capture clinical heterogeneity, however this comes with a cost. Samples derived from diverse genetic backgrounds can increase variability and make replication difficult. This variability may also increase the need for multiple donors, something that is not always possible.

Clearly, no model is perfect and there are imperfections in organoid technology, both generic and tissue specific. These inconsistencies will need to be ironed out, but it appears the organoid field is moving towards standardisation, freeing researchers from tool development and allowing them to focus on answering pivotal biological questions.

technology perfectly lends itself to the generation of novel sources of beta cells or the production of new cell-based delivery systems for insulin. These opportunities and the current state of the field are well described elsewhere [40-42]. There are, however, exciting opportunities beyond cell-based treatments of insulin-dependent diabetes. Organoids allow the modelling of primary disease tissues, insulin-sensitive tissues and peripheral tissues associated with diabetic complication, from primary sources (Fig. 2) without the need for transformed cells or large numbers of donors. We now have the tools to generate organoids from individuals with identified diabetes-associated genetic variants or to introduce these traits with CRISPR/Cas9 and use these organoids to provide a more precise evaluation of their contribution to diabetes pathogenesis. Results from these types of experiment may be informative in stratifying patients for particular interventions. These opportunities suggest that organoids may eclipse current in vitro models, transformed cell lines and short-term culture of primary tissues and provide a new understanding of diabetes pathophysiology. 


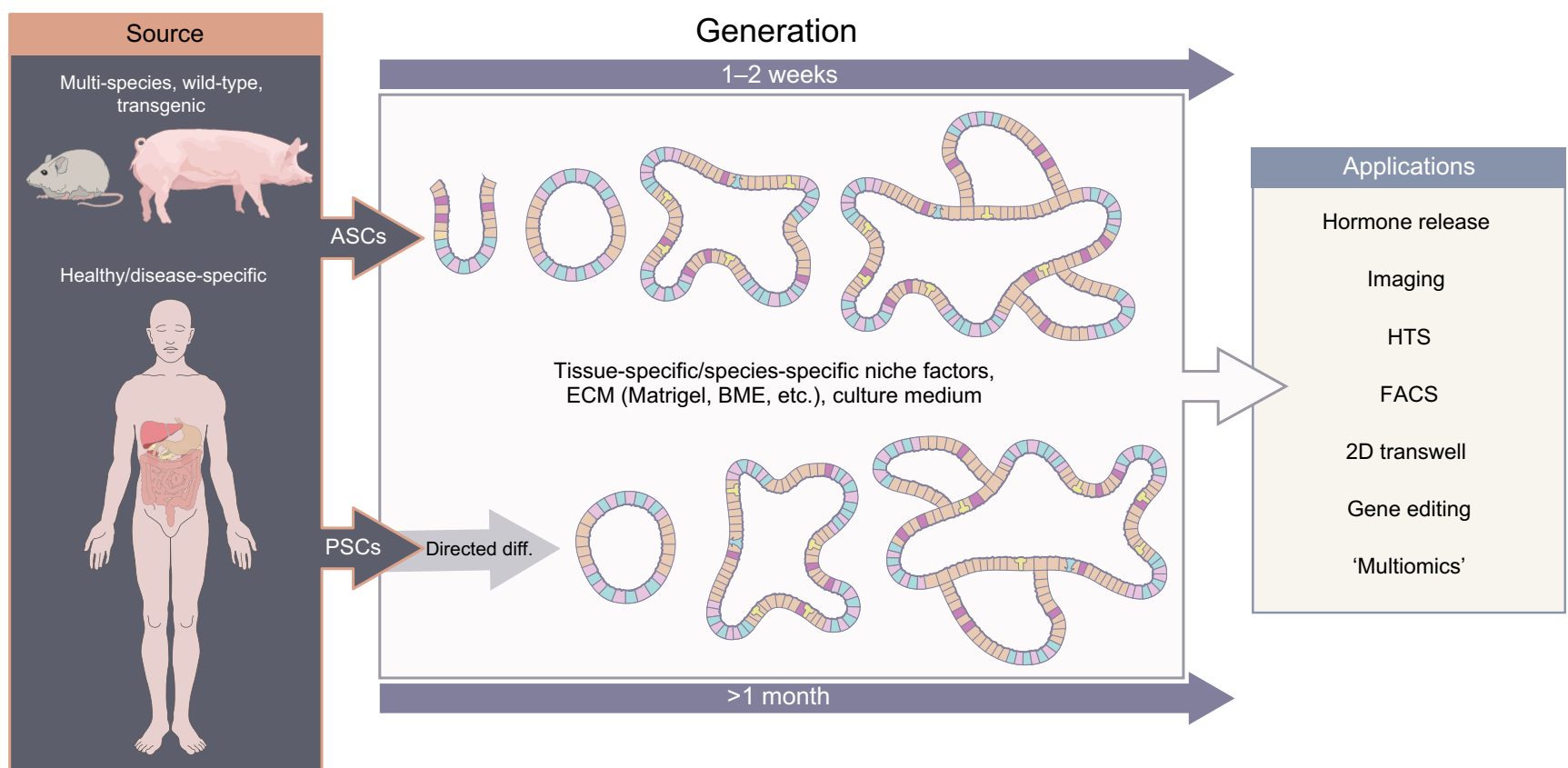

Fig. 1 Organoid generation and applications. Organoids can be generated from multiple species and multiple tissues. There are two general sources: adult tissue-resident stem cells (ASCs) and pluripotent stem cells (PSCs). Generation of PSC-derived organoids requires directed differentiation towards the tissue of interest, whereas those derived from ASCs do not. Both sources require specific niche factors and an extracellular matrix $(\mathrm{ECM})$ in which they form $3 \mathrm{D}$ multicellular organoids mimicking the

\section{Tissues controlling glucose homeostasis}

Pancreas The first pancreatic organoids were generated from mouse and human embryonic pancreatic cells by Anne Grapin-Botton's group [43, 44]. These organoids produced progenitor-biased hollow spheres that could be differentiated into branched structures containing acinar, ductal and endocrine lineages. Pancreatic organoids have also been generated from cells derived from the adult pancreas; $\mathrm{CD} 133^{+}$cells isolated from the mouse pancreas can be expanded in vitro and differentiated towards all pancreatic lineages [45, 46]. However, organoids derived from human $\mathrm{CD} 133^{+}$cells require transgenic overexpression of NGN3, MAFA and $P D X 1$ to produce endocrine lineages [47].

Generation of islet organoids by turning 2D-directed differentiation of PSCs into 3D structures, has met with mixed success. Introduction of suspension cultures and an airliquid interface produced immature beta cells that did not secrete insulin [48, 49]. In contrast, 3D islet-like organoids generated from either human embryonic stem cells [50] or from spontaneously formed endocrine cell clusters produced by stepwise differentiation of human PSCs [51] released insulin in response to glucose in vitro and in vivo. More recent efforts have introduced synthetic hydrogels [52] or co-cultures with HUVECs and mesenchymal stem cells (MSCs) combined with a self-condensation system [53]. These more tissue of interest. The schematic shows archetypal intestinal organoid development; the different colours indicate different cell types. Both types of organoid can be utilised in many downstream methods, as shown (this list is not exhaustive). BME, Basement Membrane Extract; diff., differentiation; FACS, fluorescence-activated cell sorting; HTS, high-throughput screening. This figure is available as part of a downloadable slideset

advanced systems produced islet organoids with increased complexity and maturity, including endothelial cells and vascularisation.

Islet organoids provide potential improvements over the traditional pancreatic beta cell lines as they better mimic islet architecture and morphology. However, their apparent immaturity remains their major drawback. Islet organoids often do not recapitulate nutrient-stimulated insulin secretion adequately. As such, the current technology is not ready for prime-time functional exploration, leaving primary islets as the gold standard tool for assessing islet hormone secretion.

Pancreatic organoids are currently better suited to understanding pancreatic morphogenesis and differentiation. For example, a functional genetic screen in organoids derived from $\mathrm{SOX}^{+}$progenitors identified $\operatorname{Prdm} 16$ as a novel regulator of islet development [54]. Pancreatic organoids could also provide a platform for drug screening and personalised medicine. PSC-derived organoids have been used to model pancreatic facets of cystic fibrosis and to screen a set of cystic fibrosis transmembrane conductance regulator (CFTR) activators [34]. It is also easy to envisage how organoids could help deepen our understanding of the processes that lead to immune destruction of beta cells or provide more precise details as to how genetic susceptibility loci may interact with the immune system to drive disease initiation and progression. Modelling these immune interactions could range from the 


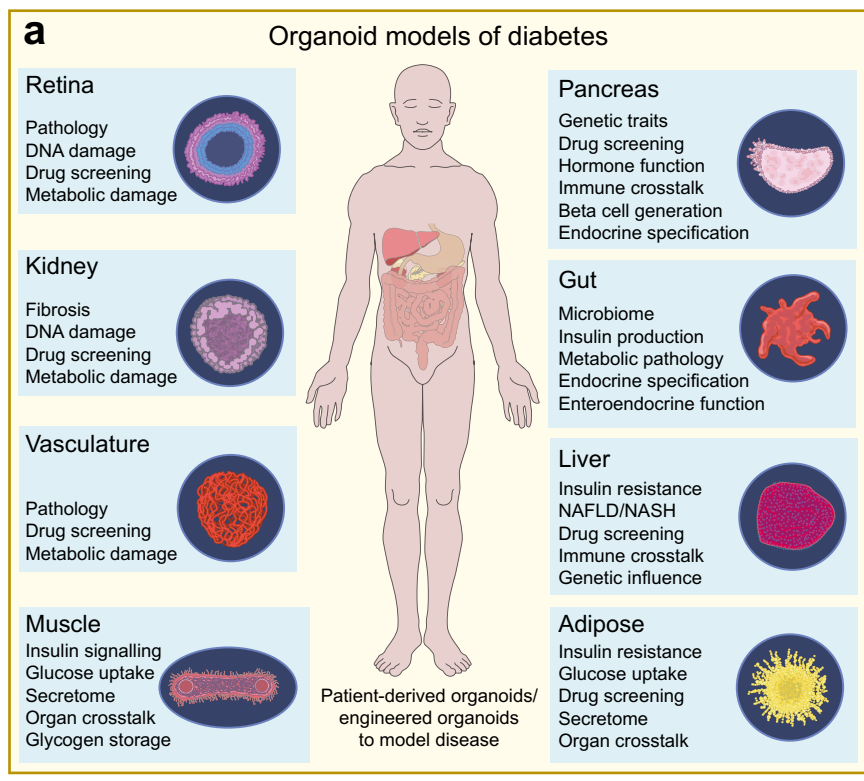

Fig. 2 Mini-me: modelling diabetes in 3D. Diabetes is a multi-organ disease and organoids present an opportunity to generate models that more closely recapitulate its pathology. (a) Organoids can be generated from multiple tissues to allow the modelling of disease progression, investigation of genetic associations, screening of drugs and probing of

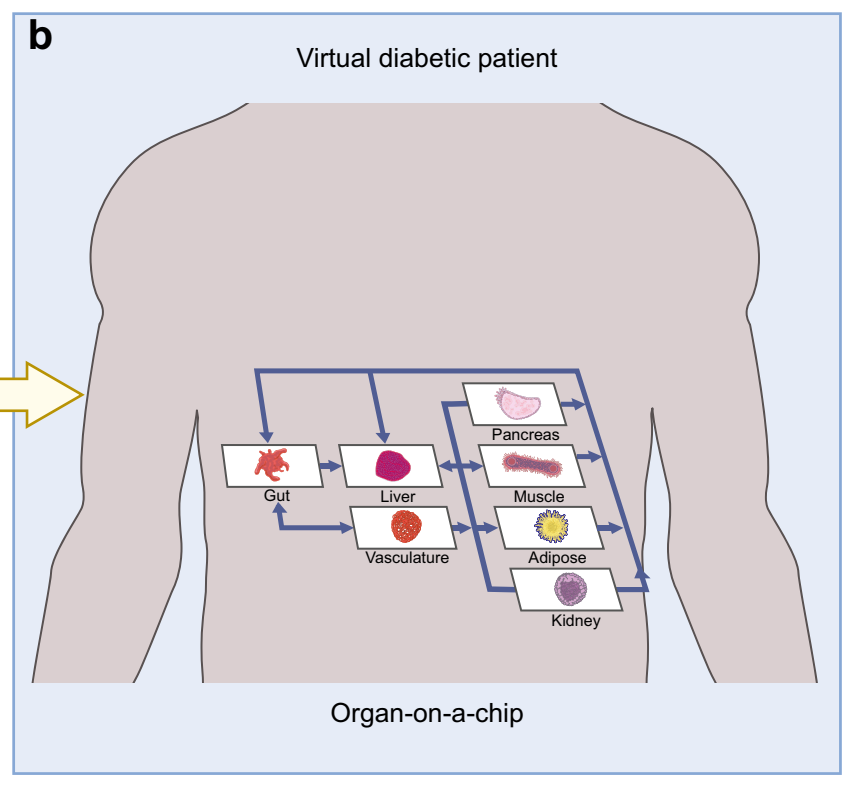

mechanisms. (b) In the future, combining organoid technology and bioengineering may make it possible to model inter-organ communication in diabetes pathogenesis, creating a virtual diabetic patient on a chip. The image in (b) is adapted from [107], with permission from Elsevier. This figure is available as part of a downloadable slideset

sensing, transport and absorption, lipid transport, hormone secretion and intracellular signalling processes [62]. The organoid platform will also help the microbiome field explore mechanisms of action. Microbial diversity is reduced in obesity, but we lack an understanding of the pathological implications. Protocols that give access to the apical (luminal) side of the organoid allow the controlled investigation of the microbiome and its metabolites [31, 39]. As yet, the generation of organoids derived from obese and/or diabetic individuals or those pre- and post-bariatric surgery, for example, have not been leveraged, but the platform offers a unique opportunity to ask critical questions of the role of the gut in the pathogenesis of metabolic disease and in the identification of mechanisms of metabolic surgeries or interventions. Finally, intestinal organoids may provide a finer understanding of the metabolic impact of nutrients on epithelial function at single cell and tissue resolution.

Liver The liver plays a central role in glucose homeostasis. Insulin resistance in the liver directly leads to hyperglycaemia and is also implicated in the pathogenesis of non-alcoholic fatty liver disease (NAFLD) and the subsequent development of non-alcoholic steatohepatitis (NASH). Current animal models of NAFLD and NASH do not perfectly mimic natural disease progression. Human liver organoids could provide a flexible tool for modelling the development of hepatic insulin resistance, studying glucose metabolism and hormonal responsiveness in the liver and identifying the underlying mechanisms driving NAFLD and its progression to NASH. For example, organoids have been used to investigate nutrient 
The first human liver organoids were generated from human induced PSC (iPSC)-derived hepatocytes, cocultured with MSCs and endothelial cells, embedded in Matrigel. These original structures consisted mainly of proliferating hepatoblasts $[63,64]$. More recently protocols have emerged to generate organoids from either human adult bile duct-derived bipotent progenitor cells [65] or primary hepatocytes [66, 67], these approaches are reviewed in $[68,69]$. Steps to model NAFLD and NASH are under way. Exposing liver organoids from multiple species to fatty acids causes lipid accumulation, demonstrating proof of principle that organoids can be used to model aspects of NAFLD [70]. More recently, a comprehensive human model of steatohepatitis has been described by Takanori Takebe. Using healthy and diseased iPSCs, multicellular human liver organoids were derived, which, when exposed to NEFA, exhibited lipid accumulation, inflammation and fibrosis in a successive manner - key features of human steatohepatitis. This phenotype could be reversed with farnesoid $\mathrm{X}$ receptor (FXR)-treatment [71]. It is hoped that such a platform could be used to understand the mechanisms behind the progression of NAFLD to NASH and identify novel treatments for NAFLD/NASH, which currently have no approved pharmacological options.

Muscle The use of 3D primary tissue-derived cultures to model skeletal muscle in vitro pre-dates the modern organoid era. Vandenburgh et al. pioneered the development of bioartificial muscles (BAMs) generated by suspending myoblasts (muscle progenitor cells), isolated from muscle biopsies, in collagen/Matrigel and then casting them in a silicone mould containing two end attachment sites [72-74]. Following differentiation, parallel arrays of myofibres aligned in the direction of the attachment points and contracted when stimulated, but their size was limited because of the lack of a vasculature. This was addressed using a co-culture system containing HUVECs, which produced organoids consisting of aligned fibres with an integrated endothelial network [75]. However, human myoblasts have a limited expansion potential and an unstable differentiated state. To overcome these issues, several protocols have emerged for PSC-derived muscle organoids (reviewed in [76]). These organoids develop myobundles, exhibit contractility following electrical stimulation and can be engineered to include a vasculature and a nervous system [77].

These cultures have the potential to model insulin resistance in 3D but have only been studied in 2D. Iovino et al. generated myotubes from healthy volunteers and individuals with Donohue syndrome, a genetic disorder associated with mutations in the insulin receptor [78]. The myotubes derived from individuals with Donohue syndrome exhibited defects in insulin signalling, glucose uptake and glycogen accumulation, as well as insulin-regulated gene expression. In the future the challenge will be to model insulin resistance in human skeletal muscle organoids generated from diabetic primary or human PSC-derived myoblasts to better understand the development of insulin resistance and its consequences.

Adipose tissue Adipose tissue is a prominent site of insulin resistance in type 2 diabetic patients and is associated with increased chronic inflammation. Development of a human in vitro model to study the pathogenesis of adipose tissue in metabolic disease would be advantageous. There have been various attempts to generate $3 \mathrm{D}$ adipose cultures. Early protocols co-cultured human adipose stromal cells with HUVECS or used lipoaspirates and embedded them in either silk scaffolds or hydrogels $[79,80]$. Differentiation of these cultures allowed lipid accumulation and these cultures secreted leptin, the archetypal adipokine. Other groups used adipose progenitors derived from the stromal-vascular fraction of human white adipose tissue and self-organised them into spheroids in hanging drops [81] or by first stirring and then embedding them in Matrigel they generated self-organised vascularised organoids [82]. These novel protocols open the door to using long-term patient-derived adipose cultures to explore the pathology of adipose tissue in metabolic disease.

\section{Modelling diabetic complications}

Many of the long-term complications associated with diabetes are caused by microvascular damage, which leads to nephropathy, retinopathy and diabetic neuropathy. A paucity of accurate models that mimic the functional and molecular pathology of these complications has hampered our understanding of the disease mechanism involved and how the complications could be managed or prevented. Organoids may offer an opportunity to address this.

Exposure to hyperglycaemia causes abnormal thickening of the basement membrane of the vasculature, impairing the delivery of oxygen and nutrients to tissues, causing inflammation and damage. Generation of iPSC-derived human blood vessel organoids recapitulates the abnormal thickening of the basement membrane when they are exposed to hyperglycaemia. A subsequent drug screen using this model has identified a novel pathway for drug targeting, underscoring the potential of organoid disease modelling [83].

Human and mouse PSC-derived kidney organoids have been generated using a number of different protocols [84-86]. However, these protocols either failed to recapitulate the necessary cell types or produced disconnected nephrons and collecting ducts. Using optimised stepwise differentiation to separately generate nephron and ureteric bud progenitors before mixing in culture with embryo-derived stromal cells produced more refined kidney organoids [87]. In depth reviews of the protocols used for generation of kidney 
organoids and their uses are available [88-91]. Kidney organoids have yet to be leveraged for investigating diabetic nephropathy but there are several groups working in this area. The European Commission and the National Centre for the Replacement, Refinement and Reduction of Animals in Research (NC3Rs) have awarded funding for projects to establish in vitro models of diabetic nephropathy and kidney damage using PSC-derived organoids [92, 93]. The Diabetic Complications Consortium have also funded a project to model kidney fibrosis [94]. It will be exciting to see the outcomes of these innovative projects.

The human retina is a complex organ with no regenerative capacity, making it particularly sensitive to damage. Retinal organoids can be generated from both mouse and human ESCs and human iPSCs, which, when embedded in Matrigel, spontaneously form hemispherical epithelial optic vesicle, that invaginate and form the optic cup [95-97]. Further protocol refinement has enabled the generation of $3 \mathrm{D}$ retinal cups containing mature photoreceptors, an outersegment-disc and demonstrable photosensitivity [98]. In depth information about retinal organoids is well described in other reviews [99-101]. Patient-derived retinal organoids offer an opportunity to more precisely understand the pathophysiology of diabetic retinopathy provide a platform for drug screening and will enable the exploration of genomic variants that render some diabetic patients more susceptible to retinal damage.

\section{The future in 3D}

The arguments for applying organoid technology to diabetes research are persuasive. This technology has facilitated the generation of high-fidelity models of virtually any tissue in the body. They offer unprecedented predictive power over traditional 2D models, promise to bring speed and reliability to drug discovery and enable the discovery of novel disease mechanisms. However, organs do not exist in isolation; interorgan crosstalk is highly relevant to pathophysiology, particularly for diseases like diabetes, which affect multiple organ systems. As such, organoids cannot replace whole body studies, but the field of bioengineering may provide opportunities to move towards a virtual diabetic individual. Organ-on-achip technologies have rapidly developed in a short space of time [102]. The technology allows the simultaneous culture of cells from different organs on a microfluidic chip, allowing the precise control of flow between compartments, nutrient supply, shear stress and local mechanical and electrical properties [103]. These systems have often relied on 2D cultures; the challenge now will be to combine organ-on-a-chip technology and 3D organoid technology. Human islet organoids derived from human iPSCs have been generated on an organon-a-chip platform [104]. PSCs were initially differentiated into embryonic bodies followed by endoderm differentiation, islet differentiation and maturation. Theses organoids contained heterogeneous islet-like components and functionalities and may resemble their native tissue more closely than static organoid cultures. There are several commercial companies who have developed specialised organ-on-a-chip equipment, ranging from simple multi-well plate systems using gravity to drive flow [105], to complete chip-based pump perfused technologies [106]. It is easy to envisage a future where we will be able to link key human organoid tissue models using chip-based technology to investigate organlevel communication in the pathogenesis of diabetes. Organoid technology is poised to enable researchers to transform our understanding and treatment of diabetes.

Funding Work in the authors' laboratories is supported by European Foundation for the Study of Diabetes (EFSD) and JDRF. PFP is funded as part of the MRC Doctoral Training Partnership programme.

Authors' relationships and activities The authors declare that there are no relationships or activities that might bias, or be perceived to bias, their work.

Contribution statement All authors were responsible for drafting the article and revising it critically for important intellectual content. All authors approved the version to be published.

Open Access This article is licensed under a Creative Commons Attribution 4.0 International License, which permits use, sharing, adaptation, distribution and reproduction in any medium or format, as long as you give appropriate credit to the original author(s) and the source, provide a link to the Creative Commons licence, and indicate if changes were made. The images or other third party material in this article are included in the article's Creative Commons licence, unless indicated otherwise in a credit line to the material. If material is not included in the article's Creative Commons licence and your intended use is not permitted by statutory regulation or exceeds the permitted use, you will need to obtain permission directly from the copyright holder. To view a copy of this licence, visit http://creativecommons.org/licenses/by/4.0/.

\section{References}

1. (2018) Method of the year 2017: organoids. Nat Methods 15(1):1. https://doi.org/10.1038/nmeth.4575

2. Simian M, Bissell MJ (2017) Organoids: a historical perspective of thinking in three dimensions. J Cell Biol 216(1):31-40. https:// doi.org/10.1083/jcb.201610056

3. Clevers H (2016) Modeling development and disease with organoids. Cell 165(7):1586-1597. https://doi.org/10.1016/j.cell. 2016.05.082

4. Fatehullah A, Tan SH, Barker N (2016) Organoids as an in vitro model of human development and disease. Nat Cell Biol 18(3): 246-254. https://doi.org/10.1038/ncb3312

5. Schutgens F, Clevers H (2019) Human organoids: tools for understanding biology and treating diseases. Annu Rev Pathol 24:211234

6. Lancaster MA, Knoblich JA (2014) Organogenesis in a dish: modeling development and disease using organoid technologies. Science 345(6194):1247125. https://doi.org/10.1126/science. 1247125 
7. Lancaster MA, Huch M (2019) Disease modelling in human organoids. Dis Model Mech 12(7):dmm039347. https://doi.org/ 10.1242/dmm.039347

8. Sato T, Vries RG, Snippert HJ et al (2009) Single Lgr5 stem cells build crypt-villus structures in vitro without a mesenchymal niche. Nature 459(7244):262-265. https://doi.org/10.1038/nature07935

9. Sugimoto S, Sato T (2017) Establishment of 3D intestinal organoid cultures from intestinal stem cells. Methods Mol Biol 1612:97-105. https://doi.org/10.1007/978-1-4939-7021-6_7

10. Sato T, van Es JH, Snippert HJ et al (2011) Paneth cells constitute the niche for Lgr5 stem cells in intestinal crypts. Nature 469(7330):415-418. https://doi.org/10.1038/nature09637

11. Sato T, Stange DE, Ferrante $M$ et al (2011) Long-term expansion of epithelial organoids from human colon, adenoma, adenocarcinoma, and Barrett's epithelium. Gastroenterology 141(5):17621772. https://doi.org/10.1053/j.gastro.2011.07.050

12. Drost J, van Jaarsveld RH, Ponsioen B et al (2015) Sequential cancer mutations in cultured human intestinal stem cells. Nature 521(7550):43-47. https://doi.org/10.1038/nature14415

13. McCracken KW, Howell JC, Wells JM, Spence JR (2011) Generating human intestinal tissue from pluripotent stem cells in vitro. Nat Protoc 6(12):1920-1928. https://doi.org/10.1038/ nprot. 2011.410

14. Spence JR, Mayhew CN, Rankin SA et al (2011) Directed differentiation of human pluripotent stem cells into intestinal tissue in vitro. Nature 470(7332):105-109. https://doi.org/10.1038/ nature09691

15. Wells JM, Spence JR (2014) How to make an intestine. Development 141(4):752-760. https://doi.org/10.1242/dev. 097386

16. Munera JO, Wells JM (2017) Generation of gastrointestinal organoids from human pluripotent stem cells. Methods Mol Biol 1597:167-177

17. Takebe T, Wells JM (2019) Organoids by design. Science 364(6444):956-959. https://doi.org/10.1126/science.aaw7567

18. Sinagoga KL, Wells JM (2015) Generating human intestinal tissues from pluripotent stem cells to study development and disease. EMBO J 34(9):1149-1163. https://doi.org/10.15252/ embj.201490686

19. Drost J, Clevers H (2017) Translational applications of adult stem cell-derived organoids. Development 144(6):968-975. https://doi. org/10.1242/dev. 140566

20. Artegiani B, Clevers H (2018) Use and application of 3Dorganoid technology. Hum Mol Genet 27(R2):R99-R107. https://doi.org/10.1093/hmg/ddy187

21. Takahashi $\mathrm{T}$ (2019) Organoids for drug discovery and personalized medicine. Annu Rev Pharmacol Toxicol 59:447-462. https:// doi.org/10.1146/annurev-pharmtox-010818-021108

22. Driehuis E, Clevers H (2017) CRISPR/Cas 9 genome editing and its applications in organoids. Am J Physiol Gastrointest Liver Physiol 312(3):G257-G265. https://doi.org/10.1152/ajpgi.00410. 2016

23. Gonneaud A, Asselin C, Boudreau F, Boisvert FM (2017) Phenotypic analysis of Organoids by proteomics. Proteomics 17(20):1700023. https://doi.org/10.1002/pmic.201700023

24. Basak O, Beumer J, Wiebrands K, Seno H, van Oudenaarden A, Clevers H (2017) Induced quiescence of Lgr5+ stem cells in intestinal organoids enables differentiation of hormone-producing enteroendocrine cells. Cell Stem Cell 20(2):177-190 e174. https://doi.org/10.1016/j.stem.2016.11.001

25. Lindeboom RG, van Voorthuijsen L, Oost KC et al (2018) Integrative multi-omics analysis of intestinal organoid differentiation. Mol Syst Biol 14:e8227

26. Dekkers JF, Alieva M, Wellens LM et al (2019) High-resolution 3D imaging of fixed and cleared organoids. Nat Protoc 14(6): 1756-1771. https://doi.org/10.1038/s41596-019-0160-8
27. Nozaki K, Mochizuki W, Matsumoto Y et al (2016) Co-culture with intestinal epithelial organoids allows efficient expansion and motility analysis of intraepithelial lymphocytes. J Gastroenterol 51(3):206-213. https://doi.org/10.1007/s00535-016-1170-8

28. Noel G, Baetz NW, Staab JF et al (2017) A primary human macrophage-enteroid co-culture model to investigate mucosal gut physiology and host-pathogen interactions. Sci Rep 7(1): 45270. https://doi.org/10.1038/srep45270

29. Workman MJ, Mahe MM, Trisno S et al (2017) Engineered human pluripotent-stem-cell-derived intestinal tissues with a functional enteric nervous system. Nat Med 23(1):49-59. https://doi. org/10.1038/nm.4233

30. Engevik KA, Matthis AL, Montrose MH, Aihara E (2018) Organoids as a model to study infectious disease. Methods Mol Biol 1734:71-81. https://doi.org/10.1007/978-1-4939-7604-1_8

31. Nigro G, Hanson M, Fevre C, Lecuit M, Sansonetti PJ (2019) Intestinal organoids as a novel tool to study microbes-epithelium interactions. Methods Mol Biol 1576:183-194. https://doi.org/10. 1007/7651_2016_12

32. Holloway EM, Capeling MM, Spence JR (2019) Biologically inspired approaches to enhance human organoid complexity. Development 146(8):dev166173. https://doi.org/10.1242/dev. 166173

33. Watson CL, Mahe MM, Munera J et al (2014) An in vivo model of human small intestine using pluripotent stem cells. Nat Med 20(11):1310-1314. https://doi.org/10.1038/nm.3737

34. Hohwieler M, Illing A, Hermann PC et al (2017) Human pluripotent stem cell-derived acinar/ductal organoids generate human pancreas upon orthotopic transplantation and allow disease modelling. Gut 66(3):473-486. https://doi.org/10.1136/gutjnl-2016312423

35. Oksdath M, Perrin SL, Bardy C et al (2018) Review: synthetic scaffolds to control the biochemical, mechanical, and geometrical environment of stem cell-derived brain organoids. APL Bioeng 2(4):041501. https://doi.org/10.1063/1.5045124

36. Bartfeld S, Bayram T, van de Wetering $M$ et al (2015) In vitro expansion of human gastric epithelial stem cells and their responses to bacterial infection. Gastroenterology 148(1):126136 e126. https://doi.org/10.1053/j.gastro.2014.09.042

37. Moon C, VanDussen KL, Miyoshi H, Stappenbeck TS (2014) Development of a primary mouse intestinal epithelial cell monolayer culture system to evaluate factors that modulate IgA transcytosis. Mucosal Immunol 7(4):818-828. https://doi.org/10.1038/mi.2013. 98

38. Wang Y, Chiang IL, Ohara TE et al (2019) Long-term culture captures injury-repair cycles of colonic stem cells. Cell 179(5): 1144-1159 e1115. https://doi.org/10.1016/j.cell.2019.10.015

39. Co JY, Margalef-Catala M, Li X et al (2019) Controlling epithelial polarity: a human enteroid model for host-pathogen interactions. Cell Rep 26(9):2509-2520 e2504. https://doi.org/10.1016/j. celrep.2019.01.108

40. Dayem AA, Lee SB, Kim K, Lim KM, Jeon TI, Cho SG (2019) Recent advances in organoid culture for insulin production and diabetes therapy: methods and challenges. BMB Rep 52(5):295303

41. Bakhti M, Bottcher A, Lickert H (2019) Modelling the endocrine pancreas in health and disease. Nat Rev Endocrinol 15(3):155171. https://doi.org/10.1038/s41574-018-0132-z

42. Shahjalal HM, Abdal Dayem A, Lim KM, Jeon TI, Cho SG (2018) Generation of pancreatic beta cells for treatment of diabetes: advances and challenges. Stem Cell Res Ther 9(1):355. https://doi.org/10.1186/s13287-018-1099-3

43. Greggio C, De Franceschi F, Figueiredo-Larsen M et al (2013) Artificial three-dimensional niches deconstruct pancreas development in vitro. Development 140(21):4452-4462. https://doi.org/ 10.1242/dev.096628 
44. Bonfanti P, Nobecourt E, Oshima M et al (2015) Ex vivo expansion and differentiation of human and mouse fetal pancreatic progenitors are modulated by epidermal growth factor. Stem Cells Dev 24(15):1766-1778. https://doi.org/10.1089/scd.2014. 0550

45. Jin L, Feng T, Shih HP et al (2013) Colony-forming cells in the adult mouse pancreas are expandable in Matrigel and form endocrine/acinar colonies in laminin hydrogel. Proc Natl Acad Sci U S A 110(10):3907-3912. https://doi.org/10.1073/pnas. 1301889110

46. Jin L, Feng T, Zerda R, Chen CC, Riggs AD, Ku HT (2014) In vitro multilineage differentiation and self-renewal of single pancreatic colony-forming cells from adult C57BL/6 mice. Stem Cells Dev 23(8):899-909. https://doi.org/10.1089/scd.2013.0466

47. Lee J, Sugiyama T, Liu Y et al (2013) Expansion and conversion of human pancreatic ductal cells into insulin-secreting endocrine cells. Elife 2:e00940. https://doi.org/10.7554/eLife.00940

48. Pagliuca FW, Millman JR, Gurtler M et al (2014) Generation of functional human pancreatic beta cells in vitro. Cell 159(2):428 439. https://doi.org/10.1016/j.cell.2014.09.040

49. Russ HA, Parent AV, Ringler JJ et al (2015) Controlled induction of human pancreatic progenitors produces functional beta-like cells in vitro. EMBO J 34(13):1759-1772. https://doi.org/10. 15252/embj.201591058

50. Shim JH, Kim J, Han J et al (2015) Pancreatic islet-like threedimensional aggregates derived from human embryonic stem cells ameliorate hyperglycemia in Streptozotocin-induced diabetic mice. Cell Transplant 24(10):2155-2168. https://doi.org/10. 3727/096368914X685438

51. Kim Y, Kim H, Ko UH et al (2016) Islet-like organoids derived from human pluripotent stem cells efficiently function in the glucose responsiveness in vitro and in vivo. Sci Rep 6(1):35145. https://doi.org/10.1038/srep35145

52. Candiello J, Grandhi TSP, Goh SK et al (2018) 3D heterogeneous islet organoid generation from human embryonic stem cells using a novel engineered hydrogel platform. Biomaterials 177:27-39. https://doi.org/10.1016/j.biomaterials.2018.05.031

53. Takahashi Y, Sekine K, Kin T, Takebe T, Taniguchi H (2018) Selfcondensation culture enables vascularization of tissue fragments for efficient therapeutic transplantation. Cell Rep 23(6):1620 1629. https://doi.org/10.1016/j.celrep.2018.03.123

54. Sugiyama T, Benitez CM, Ghodasara A et al (2013) Reconstituting pancreas development from purified progenitor cells reveals genes essential for islet differentiation. Proc Natl Acad Sci U S A 110(31):12691-12696. https://doi.org/10.1073/ pnas. 1304507110

55. Powell N, Pantazi E, Pavlidis P et al (2019) Interleukin-22 orchestrates a pathological endoplasmic reticulum stress response transcriptional programme in colonic epithelial cells. Gut 69(3):578590. https://doi.org/10.1136/gutjnl-2019-318483

56. Ibiza S, Garcia-Cassani B, Ribeiro H et al (2016) Glial-cellderived neuroregulators control type 3 innate lymphoid cells and gut defence. Nature 535(7612):440-443. https://doi.org/10.1038/ nature 18644

57. Neal JT, Li X, Zhu J et al (2018) Organoid modeling of the tumor immune microenvironment. Cell 175(7):1972-1988. https://doi. org/10.1016/j.cell.2018.11.021

58. Tsakmaki A, FPPaBG (2017) 3D intestinal organoids in metabolic research: Virtual reality in a dish. Curr Opin Pharmacol 37:51-58. https://doi.org/10.1016/j.coph.2017.09.003

59. Chang-Graham AL, Danhof HA, Engevik MA et al (2019) Human intestinal Enteroids with inducible Neurogenin-3 expression as a novel model of gut hormone secretion. Cell Mol Gastroenterol Hepatol 8(2):209-229. https://doi.org/10.1016/j. jcmgh.2019.04.010
60. Chen YJ, Finkbeiner SR, Weinblatt D et al (2014) De novo formation of insulin-producing "neo-beta cell islets" from intestinal crypts. Cell Rep 6(6):1046-1058. https://doi.org/10.1016/j. celrep.2014.02.013

61. Bouchi R, Foo KS, Hua H et al (2014) FOXO1 inhibition yields functional insulin-producing cells in human gut organoid cultures. Nat Commun 5(1):4242. https://doi.org/10.1038/ncomms5242

62. Zietek T, Rath E, Haller D, Daniel H (2015) Intestinal organoids for assessing nutrient transport, sensing and incretin secretion. Sci Rep 5(1):16831. https://doi.org/10.1038/srep16831

63. Takebe T, Sekine K, Enomura M et al (2013) Vascularized and functional human liver from an iPSC-derived organ bud transplant. Nature 499(7459):481-484. https://doi.org/10.1038/ nature 12271

64. Takebe T, Sekine K, Kimura M et al (2017) Massive and reproducible production of liver buds entirely from human pluripotent stem cells. Cell Rep 21(10):2661-2670. https://doi.org/10.1016/j. celrep.2017.11.005

65. Huch M, Gehart H, van Boxtel R et al (2015) Long-term culture of genome-stable bipotent stem cells from adult human liver. Cell 160(1-2):299-312. https://doi.org/10.1016/j.cell.2014.11.050

66. Peng WC, Logan CY, Fish M et al (2018) Inflammatory cytokine $\mathrm{TNF} \alpha$ promotes the long-term expansion of primary hepatocytes in 3D culture. Cell 175(6):1607-1619. https://doi.org/10.1016/j. cell.2018.11.012

67. $\mathrm{Hu} \mathrm{H}$, Gehart H, Artegiani B et al (2018) Long-term expansion of functional mouse and human hepatocytes as 3D organoids. Cell 175(6):1591-1606. https://doi.org/10.1016/j.cell.2018.11.013

68. Prior N, Inacio P, Huch M (2019) Liver organoids: from basic research to therapeutic applications. Gut 68(12):2228-2237. https://doi.org/10.1136/gutjnl-2019-319256

69. Akbari S, Arslan N, Senturk S, Erdal E (2019) Next-generation liver medicine using Organoid models. Front Cell Dev Biol 7:345. https://doi.org/10.3389/fcell.2019.00345

70. Kruitwagen HS, Oosterhoff LA, Vernooij I et al (2017) Long-term adult feline liver Organoid cultures for disease modeling of hepatic Steatosis. Stem Cell Rep 8(4):822-830. https://doi.org/10.1016/j. stemcr.2017.02.015

71. Ouchi R, Togo S, Kimura M et al (2019) Modeling Steatohepatitis in humans with pluripotent stem cell-derived Organoids. Cell Metab 30(2):374-384. https://doi.org/10.1016/j.cmet.2019.05. 007

72. Vandenburgh H, DelTatto M, Shansky J et al (1996) Tissueengineered skeletal muscle organoids for reversible gene therapy. Hum Gene Ther 7(17):2195-2200. https://doi.org/10.1089/hum. 1996.7.17-2195

73. Vandenburgh H, Shansky J, Del Tatto M, Chromiak J (1999) Organogenesis of skeletal muscle in tissue culture. Methods Mol Med 18:217-225. https://doi.org/10.1385/0-89603-516-6:217

74. Powell CA, Smiley BL, Mills J, Vandenburgh HH (2002) Mechanical stimulation improves tissue-engineered human skeletal muscle. Am J Physiol Cell Physiol 283(5):C1557-C1565. https://doi.org/10.1152/ajpcell.00595.2001

75. Gholobova D, Decroix L, Van Muylder V et al (2015) Endothelial network formation within human tissue-engineered skeletal muscle. Tissue Eng Part A 21(19-20):2548-2558. https://doi.org/ 10.1089/ten.TEA.2015.0093

76. Chal J, Pourquie O (2017) Making muscle: skeletal myogenesis in vivo and in vitro. Development 144(12):2104-2122. https://doi. org/10.1242/dev.151035

77. Maffioletti SM, Sarcar S, Henderson ABH et al (2018) Threedimensional human iPSC-derived artificial skeletal muscles model muscular dystrophies and enable multilineage tissue engineering. Cell Rep 23(3):899-908. https://doi.org/10.1016/j.celrep.2018.03. 091 
78. Iovino S, Burkart AM, Warren L, Patti ME, Kahn CR (2016) Myotubes derived from human-induced pluripotent stem cells mirror in vivo insulin resistance. Proc Natl Acad Sci U S A 113(7):1889-1894. https://doi.org/10.1073/pnas.1525665113

79. Pellegrinelli V, Rouault C, Veyrie N, Clement K, Lacasa D (2014) Endothelial cells from visceral adipose tissue disrupt adipocyte functions in a three-dimensional setting: partial rescue by angiopoietin-1. Diabetes 63(2):535-549. https://doi.org/10.2337/ db13-0537

80. Abbott RD, Wang RY, Reagan MR et al (2016) The use of silk as a scaffold for mature, sustainable unilocular adipose 3D tissue engineered systems. Adv Healthc Mater 5(13):1667-1677. https://doi.org/10.1002/adhm.201600211

81. Klingelhutz AJ, Gourronc FA, Chaly A et al (2018) Scaffold-free generation of uniform adipose spheroids for metabolism research and drug discovery. Sci Rep 8(1):523. https://doi.org/10.1038/ s41598-017-19024-z

82. Muller S, Ader I, Creff J et al (2019) Human adipose stromalvascular fraction self-organizes to form vascularized adipose tissue in 3D cultures. Sci Rep 9(1):7250. https://doi.org/10.1038/ s41598-019-43624-6

83. Wimmer RA, Leopoldi A, Aichinger M et al (2019) Human blood vessel organoids as a model of diabetic vasculopathy. Nature 565(7740):505-510. https://doi.org/10.1038/s41586-018-0858-8

84. Taguchi A, Kaku Y, Ohmori T et al (2014) Redefining the in vivo origin of metanephric nephron progenitors enables generation of complex kidney structures from pluripotent stem cells. Cell Stem Cell 14(1):53-67. https://doi.org/10.1016/j.stem.2013.11.010

85. Takasato M, Er PX, Chiu HS et al (2015) Kidney organoids from human iPS cells contain multiple lineages and model human nephrogenesis. Nature 526(7574):564-568. https://doi.org/10. 1038/nature15695

86. Morizane R, Lam AQ, Freedman BS, Kishi S, Valerius MT, Bonventre JV (2015) Nephron organoids derived from human pluripotent stem cells model kidney development and injury. Nat Biotechnol 33(11):1193-1200. https://doi.org/10.1038/nbt.3392

87. Taguchi A, Nishinakamura R (2017) Higher-order kidney organogenesis from pluripotent stem cells. Cell Stem Cell 21(6):730 746 e736. https://doi.org/10.1016/j.stem.2017.10.011

88. Nishinakamura R (2019) Human kidney organoids: progress and remaining challenges. Nat Rev Nephrol 15(10):613-624. https:// doi.org/10.1038/s41581-019-0176-x

89. Islam M, Nishinakamura R (2019) How to rebuild the kidney: recent advances in kidney organoids. J Biochem 166(1):7-12. https://doi.org/10.1093/jb/mvz021

90. Little MH, Combes AN (2019) Kidney organoids: accurate models or fortunate accidents. Genes Dev 33(19-20):13191345. https://doi.org/10.1101/gad.329573.119

91. Little MH, Hale LJ, Howden SE, Kumar SV (2019) Generating kidney from stem cells. Annu Rev Physiol 81:335-357. https:// doi.org/10.1146/annurev-physiol-020518-114331

92. Dimensions (2019) Diabetic nephropathy modelling in hESCderived 3D kidney organoids. Available from https://app. dimensions.ai/details/grant/grant.7926732. Accessed 1 September 2019

93. National Centre for the Replacement Refinement \& Reduction of Animals in Research (2019) Development of novel models of kidney damage using induced human pluripotent stem cells. Available from www.nc3rs.org.uk/development-novel-modelskidney-damage-using-induced-human-pluripotent-stem-cells. Accessed 1 September 2019

94. DiaComp (2018) Modeling diabetic kidney fibrosis with kidney organoids derived from human pluripotent stem cells. Available from www.diacomp.org/shared/showSubContractAbstract.aspx? id=3799. Accessed 1 September 2019

95. Eiraku M, Takata N, Ishibashi H et al (2011) Self-organizing optic-cup morphogenesis in three-dimensional culture. Nature 472(7341):51-56. https://doi.org/10.1038/nature09941

96. Nakano T, Ando S, Takata $\mathrm{N}$ et al (2012) Self-formation of optic cups and storable stratified neural retina from human ESCs. Cell Stem Cell 10(6):771-785. https://doi.org/10.1016/j.stem.2012.05. 009

97. Meyer JS, Howden SE, Wallace KA et al (2011) Optic vesicle-like structures derived from human pluripotent stem cells facilitate a customized approach to retinal disease treatment. Stem Cells 29(8):1206-1218. https://doi.org/10.1002/stem.674

98. Zhong X, Gutierrez C, Xue T et al (2014) Generation of threedimensional retinal tissue with functional photoreceptors from human iPSCs. Nat Commun 5(1):4047. https://doi.org/10.1038/ ncomms 5047

99. Achberger K, Haderspeck JC, Kleger A, Liebau S (2019) Stem cell-based retina models. Adv Drug Deliv Rev 140:33-50. https:// doi.org/10.1016/j.addr.2018.05.005

100. Llonch S, Carido M, Ader M (2018) Organoid technology for retinal repair. Dev Biol 433(2):132-143. https://doi.org/10.1016/ j.ydbio.2017.09.028

101. Jin ZB, Gao ML, Deng WL et al (2019) Stemming retinal regeneration with pluripotent stem cells. Prog Retin Eye Res 69:38-56. https://doi.org/10.1016/j.preteyeres.2018.11.003

102. Ingber DE (2018) Developmentally inspired human 'organs on chips'. Development 145(16):dev156125. https://doi.org/10. $1242 / \operatorname{dev} .156125$

103. Sosa-Hernandez JE, Villalba-Rodriguez AM, Romero-Castillo KD et al (2018) Organs-on-a-chip module: a review from the development and applications perspective. Micromachines 9(10):536. https://doi.org/10.3390/mi9100536

104. Tao T, Wang Y, Chen W et al (2019) Engineering human islet organoids from iPSCs using an organ-on-chip platform. Lab Chip 19(6):948-958. https://doi.org/10.1039/c8lc01298a

105. van Duinen V, Trietsch SJ, Joore J, Vulto P, Hankemeier T (2015) Microfluidic 3D cell culture: from tools to tissue models. Curr Opin Biotechnol 35:118-126. https://doi.org/10.1016/j.copbio. 2015.05.002

106. Bhatia SN, Ingber DE (2014) Microfluidic organs-on-chips. Nat Biotechnol 32(8):760-772. https://doi.org/10.1038/nbt.2989

107. Huh D, Hamilton GA, Ingber DE (2011) From 3D cell culture to organs-on-chips. Trends Cell Biol 21(12):745-754. https://doi. org/10.1016/j.tcb.2011.09.005

Publisher's note Springer Nature remains neutral with regard to jurisdictional claims in published maps and institutional affiliations. 